\title{
Development of a scale assessing Beliefs About ThirdHand Smoke (BATHS)
}

\author{
Regine Haardörfer ${ }^{1 *}$, Carla J. Berg ${ }^{1}$, Cam Escoffery ${ }^{1}$, Łucja T. Bundy ${ }^{1}$, Melbourne Hovell ${ }^{2}$ and Michelle C. Kegler ${ }^{1}$
}

\begin{abstract}
Background: Similarly to secondhand smoke (SHS), thirdhand smoke (THS) beliefs may be correlated with smoking behaviors and smokefree policies in the home. Thus, there is a need to develop and validate measures to assess beliefs about THS.

Methods: A list of 19 items related to THS were generated by an expert panel and tested in a pilot study. Based on results from an exploratory factor analysis, two factors emerged: THS persistence in the environment and THS impact on health. The scale was reduced to nine items, which showed no differential item functioning by smoking status or smoking ban status in the home. The nine items and the two factor structure were tested in a validation sample from a smoke-free homes intervention that included THS educational materials.
\end{abstract}

Results: The 9-item scale showed excellent internal consistency. Confirmatory factor analysis indicated good model fit for the two factor solution in a low-income population. Tests of construct validity indicated differences due to exposure to the smoke-free homes intervention, by smoking status, whether participants own or rent their home, and smoking ban status in the home.

Conclusions: The BATHS scale offers researchers a valid and reliable tool to assess THS beliefs.

Keywords: Thirdhand smoke, Scale development, Secondhand/environmental exposure

\section{Background}

Thirdhand smoke (THS) is a recent discovery that contributes to indoor pollution and compromises health [1]. The $3 \mathrm{R}$ definition of THS describe it as the residual pollutant that remains on a variety of indoor surfaces and in dust, is re-emitted back into a gas phase, and reacts with other compounds in the air [2]. THS exposure may occur long after secondhand smoke appears (SHS) [3]. It can linger on surfaces long after cigarettes have been extinguished [4-6]. Matt (2011) [7] found that even weeks and months after a cigarette has been smoked, harmful particulates remain on countertops, floors, upholstery, carpets, clothing, and other surfaces. Furthermore, removal of nicotine residues from carpet and walls has been found to be nearly impossible [8], leading to continual exposure to THS. In addition, when the nicotine in tobacco smoke sorbed to indoor surfaces reacts with nitrous acid, a common component of indoor

\footnotetext{
* Correspondence: regine.haardoerfer@emory.edu

${ }^{1}$ Department of Behavioral Sciences and Health Education, Rollins School of Public Health, Emory University, 1518 Clifton Rd NE, Atlanta, GA 30322, USA Full list of author information is available at the end of the article
}

air pollutant, substantial levels of hazardous carcinogens called tobacco-specific nitrosamines (TSNAs) were formed, including NNA and NNK $[5,7,9,10]$. NNA is absent in freshly emitted SHS, but a main TSNA formed in this process. In a recent study, Bo et al. demonstrated for the first time that exposure to THS, acute or chronic, increased DNA damage (genotoxicity) in human cell lines, which could lead to formation of cancer. While research on human exposure to THS and its effects on health, behavior and social cultural consequences warrants further study $[6,8-12]$, THS poses a likely health hazard to non-smokers who are exposed.

Infants and small children are especially susceptible to THS exposure because of their immature respiratory and immune systems and likelihood to crawl and play on, inhale, touch and hand-to-mouth contaminated surfaces, such as floors and upholstery $[11,12]$. There also has been research that suggests that THS is potentially hazardous to the health of fetuses [13]. The poor are also more likely to be exposed to THS because smoking and SHS are more prevalent in low-income households. 
A recent study found the nicotine concentrations in the dust are higher in low-income non-smoking households than those with income above the median [14]. Matt et al.'s study [7] indicated that THS accumulates in smokers' homes and persists even long after the smokers move out and the homes are cleaned and repainted for new residents. Nonsmokers living in homes (houses, condos, apartments) formerly occupied by smokers are involuntarily exposed to THS [7]. Therefore, those with incomes that do not allow much free choice of rental housing might be more likely to be exposed to THS [15].

Knowledge and beliefs about SHS are correlated with smoking cessation and reduction; however, few studies have examined similar constructs about THS and how they may impact preventive smoking-related behaviors. Two studies have found no to limited awareness about THS compared to SHS [16, 17], while one of them showed that beliefs about THS' harm on children was independently associated with home smoking bans [17]. Recently, education about THS has been incorporated into interventions to promote home smoking bans [18, 19]. Drehmer [20] found that THS harm beliefs were related to more strict enforcement of smoke free bans in homes and cars and increased numbers of quit attempts, which is encouraging evidence for inclusion of THS education in interventions aiming to decrease the impact of tobacco use [21]. Based on this literature, more accurate knowledge and beliefs about THS might be associated with being a nonsmoker, having a smoke-free home, and having been exposed to education regarding the harms of THS.

A reliable and valid scale of THS beliefs might enable more precise assessment of the belief that THS is harmful. It may enable assessment of the degree to which such beliefs contribute to smoke-free home bans, avoidance of SHS in homes and other indoor spaces. The purpose of this article is to present the development of a THS Beliefs Scale and its initial psychometric properties tested among participants of a survey panel.

\section{Methods}

\section{Participants \& procedures}

Pilot sample

Data for an exploratory factor analysis came from a larger study evaluating a website aimed at helping people establish home smoking bans to make their home smoke-free. Participants were recruited in 2014 via email from Lightspeed GMI, a double-opt in access panel with panel participants from across the United States. Eligibility criteria included $18+$ years of age, able to speak English, living in a household with at least one smoker and one non-smoker (which could be a child), and allow at least some smoking in the home. Of the 17,138 invited panel members, 5138 (30.0\%) started the survey. Of those, 3950 were not eligible, 15 terminated the survey for unspecified reasons, and 599 were eligible but were terminated because the quota for non-smokers had been reached. A total of 250 eligible participants completed the survey in its entirety.

\section{Validation sample}

Data for the confirmatory factor analysis came from the 6-month follow-up data collection in 2015 from a randomized controlled trial testing the effectiveness of a smoke-free homes (SFH) intervention [22]. Participants were recruited through a 2-1-1 call center (a referral hotline that connects callers to needed social services such as utilities assistance) in Houston, Texas for a SFH intervention trial. Eligibility criteria included being 18 years or older, be able to understand English, having at least one smoker and one non-smoker living in the household, and not having a smoke-free home at baseline. At baseline, 508 participants were randomized into either the intervention or the control group. The intervention group received three mailings and one coaching call to help them create a smoke-free home. The last mailing included a flyer discussing thirdhand smoke. At the second follow-up point, 6 months after baseline, we included the reduced THS scale derived from the exploratory factor analysis from the pilot sample and all 335 participants who were reached answered the relevant questions.

\section{Measures \\ Pilot sample}

Beliefs about Thirdhand Smoke scale Questions for the tested scale were developed after a thorough literature review by an expert panel including tobacco researchers from several universities. Only one item asking about whether breathing air in a room where people smoked previously can harm the health of infants and children was directly retrieved from Winickoff [17]. The remaining 18 items were developed around 6 domains. Table 1 shows the 19 original items and answer choices. THS health impact items were used to ask about general health impact of THS on children $[6,11,17]$ and adults $[4,23]$ as well as cancer specifically $[24,25]$ with three items. Three items pertaining to THS persistence included days, weeks, and months separately $[7,20]$. Three additional items with statements about smoke particles settling with dust [11], accumulating on surfaces [4] and being absorbed into furniture and walls [8] aimed at THS accumulation in the built environment. Four items focused on THS removal with regular/thorough cleaning as well as painting, not being able to completely remove smell from rooms and smoke particles 
Table 1 Original and retained items (in bold) of the BATHS scale

\begin{tabular}{|c|c|c|c|c|c|}
\hline The next questions will ask for your opinions on the effects of smoking inside your home. & $\begin{array}{l}\text { Strongly } \\
\text { disagree }\end{array}$ & Disagree & $\begin{array}{l}\text { Not } \\
\text { sure }\end{array}$ & Agree & $\begin{array}{c}\text { Strongly } \\
\text { agree }\end{array}$ \\
\hline $\begin{array}{l}\text { Breathing air in a room today where people smoked yesterday can harm the health of infants } \\
\text { and children. }\end{array}$ & 1 & 2 & 3 & 4 & 5 \\
\hline Breathing air in a room today where people smoked yesterday can harm the health of adults. & 1 & 2 & 3 & 4 & 5 \\
\hline Particles in rooms where people smoked yesterday can cause cancer. & 1 & 2 & 3 & 4 & 5 \\
\hline Smoke particles can remain in a room for days. & 1 & 2 & 3 & 4 & 5 \\
\hline Smoke particles can remain in a room for weeks. & 1 & 2 & 3 & 4 & 5 \\
\hline Smoke particles can remain in a room for months. & 1 & 2 & 3 & 4 & 5 \\
\hline Cigarette smoke mixes and settles with dust. & 1 & 2 & 3 & 4 & 5 \\
\hline After someone smokes in a room, sticky particles are left on surfaces in the room. & 1 & 2 & 3 & 4 & 5 \\
\hline Smoke particles get absorbed into furniture and walls. & 1 & 2 & 3 & 4 & 5 \\
\hline The smell of cigarette smoke can return even after deeply cleaning a smoking room. & 1 & 2 & 3 & 4 & 5 \\
\hline Smoke stains on walls can reappear after walls have been painted. & 1 & 2 & 3 & 4 & 5 \\
\hline Removing smoke particles from carpet is almost impossible. & 1 & 2 & 3 & 4 & 5 \\
\hline Sticky smoke particles cannot be removed from surfaces with regular cleaning. & 1 & 2 & 3 & 4 & 5 \\
\hline $\begin{array}{l}\text { After smoking a cigarette, smoke particles on skin, hair, and clothing can be passed on to others } \\
\text { through touch. }\end{array}$ & 1 & 2 & 3 & 4 & 5 \\
\hline $\begin{array}{l}\text { After touching surfaces where cigarette smoke has settled, particles can enter the body through } \\
\text { the skin. }\end{array}$ & 1 & 2 & 3 & 4 & 5 \\
\hline Children who touch surfaces and then put their hands in their mouths can swallow smoke particles. & 1 & 2 & 3 & 4 & 5 \\
\hline Opening windows or using air conditioners does not eliminate all smoke particles in a room. & 1 & 2 & 3 & 4 & 5 \\
\hline Smoking only in the bathroom does not stop smoke particles from settling in other rooms. & 1 & 2 & 3 & 4 & 5 \\
\hline Having a smoke-free home will protect nonsmokers from smoke particles in your home. & 1 & 2 & 3 & 4 & 5 \\
\hline
\end{tabular}

from surfaces, carpet, and walls [8, 26, 27]. Furthermore, three items had statements that addressed THS transmission beyond breathing; these included transmission from skin, hair, and clothing $[10,11]$ as well as surfaces and children ingesting smoke particles after touching contaminated surfaces. Finally, the last three items focused on THS reduction behaviors: opening windows/ using air conditioners; smoking only in the bathroom [28]; and finally having a smoke-free home. Response options were on a 5-point Likert scale from strongly disagree to strongly agree coded as 1 through 5 .

Smoking and smoke-free home related variables Participants were asked if they currently smoked cigarettes every day, some days, or not at all. Those reporting smoking every day and some days were coded as current smokers. Smoking ban status in the home was assessed by asking "Which statement best describes the rules about smoking inside your home?" Those responding "There are no rules about smoking inside your home" and "Smoking is allowed anywhere inside your home" were coded as having no ban. Those choosing "Smoking is allowed in some places or at some times" were coded as having a partial ban.

Sociodemographics Participants' age, gender, race, marital status, education, household income, and home ownership (rent vs. own) were assessed.

\section{Validation sample}

Beliefs about Thirdhand Smoke scale For the validation sample, we included the nine items from the reduced scale based on the exploratory factor analysis (Table 1 items in bold). Response options were the same as the pilot on a 5-point Likert scale ranging from $1=$ Strongly disagree to $5=$ Strongly agree. The scale was administered at the second follow-up point, 6 months after baseline.

Smoking and smoke-free home related variables Participants in the validation sample were asked the same questions as those in the pilot sample at six-months post baseline. 
Sociodemographics Age, gender, marital status, race, education, employment status, and household income were assessed at baseline.

Smoke-free home trial group assignment Assignment to intervention and control group was random after baseline data collection. This variable was included because intervention participants received educational information regarding THS.

\section{Data analysis}

\section{Pilot sample}

Descriptive statistics for participant demographics were calculated. Distance of means from the scale mean (3) as well as standard deviations of scale items were assessed. Exploratory factor analysis including scree plots was conducted, and Cronbach's alpha for the entire scale was calculated. We reduced the scale by eliminating items with the lowest factor loadings step-by-step as long as Cronbach's alpha was above .90. Multiple Indicators Multiple Causes (MIMIC) models assessing scale invariance by smoking status and home smoking ban status, controlling for age and gender, were conducted as well.

\section{Validation sample}

Confirmatory factor analysis assessed the fit of the twofactor solution. Descriptive statistics for participant demographics were calculated. Differences between THS total and factor scores by participant characteristics were assessed using t-tests and ANOVAs.

Descriptive and exploratory factor analyses were conducted using SAS 9.4. Confirmatory factor and MIMIC analyses were conducting in MPlus 7.2.

\section{Results}

\section{Participant characteristics in the pilot sample}

Due to the sampling design, $50 \%$ of participants were current smokers living with at least one non-smoker, and $50 \%$ were current non-smokers living with at least one smoker. Most participants were married or living with a partner (67.2\%) and white (78.8\%) with at least some college $(68.8 \%)$ and an annual household income over $\$ 25,000$ (76.0\%).

\section{Beliefs about Thirdhand Smoke scale development Descriptives of the 19 item scale}

Cronbach's alpha for the entire 19-item scale was 0.95 (both raw and standardized). Exclusion of any item would reduce reliability. Item means were reasonably close to the scale mean and standard deviations were adequate (around 1.0). The scree plot and the eigenvalues were both supporting the conclusion of a two factor solution that explained $97.0 \%$ of the variance. Oblique varimax rotation yielded strong factor loadings onto two distinct factors. The first factor can be described as measuring beliefs about THS persistence in the built environment. The second factor includes items that assess beliefs about the impact of THS on health.

\section{Scale reduction}

Traditional suggestions for scale reduction start with eliminating items with low factor loadings with less than .30 [29]. No items had factor loadings this small. Hence, we sequentially reduced the scale by excluding items with the lowest factor loadings such that the final scale's reliability as measured with Cronbach's alpha was greater than 0.90. This approach reduced the scale to nine items: four items related to THS persistence in the environment and five items related to THS impact on health. The final items, their means, standard deviations and factor loadings are presented in Table 2. Factor 1 includes items that describe THS in the built environment, capturing persistence of smoke particles, accumulation of THS, and ineffectiveness of THS reduction by means other than not smoking in the house. Factor 2 includes health impact of THS and transmission of THS through means other than the air. This reduced scale had excellent overall reliability (Cronbach's alpha $=.91$ ) and strong reliability in the sub-scales (Cronbach's alpha $=.88$ for both factors).

\section{Scale invariance and differences in responses}

MIMIC models tested indicate scale invariance for smoking status (daily and non-daily smoker versus nonsmoker) as well as home smoking ban status (partial versus no ban) making the scale equally suitable for smokers and nonsmokers and those with partial and no smoking ban in their homes. In addition, there were no significant differences in THS beliefs by smoking status or home smoking ban status. However, older participants in the pilot sample were less concerned with the impact of THS on health $(\beta=-.009, p=.02)$ indicating a reduction in the THS on health score by .09 for each 10 years increase in age.

\section{Participant characteristics in the validation sample}

Demographics of participants in the validation sample are shown in Table 3. The validation sample participants had a mean age of 41.1 years $(S D=12.65)$, were mostly female (83.6\%), African American (69.9\%), unemployed (71.6\%) and reported an annual household income of $\$ 25,000$ or less $(85.7 \%)$ with $46.0 \%$ reporting a household income of $\$ 10,000$ or less. Most participants were renting their home $(77.3 \%)$ and were smokers themselves (60.3\%). About half reported a full smoking ban in their home and an additional $29.0 \%$ reported a partial ban. 
Table 2 Means, standard deviations, and factor loadings of final scale items in the validation sample

\begin{tabular}{|c|c|c|c|c|}
\hline \multirow[t]{2}{*}{ Scale item } & \multirow[t]{2}{*}{ Mean } & \multirow[t]{2}{*}{ (SD) } & \multicolumn{2}{|c|}{ Factor loadings } \\
\hline & & & THS persistence & THS health \\
\hline Smoke particles can remain in a room for weeks. & 3.65 & (0.95) & 0.759 & \\
\hline Smoke particles can remain in a room for days. & 3.89 & (0.85) & 0.749 & \\
\hline Smoke particles get absorbed into furniture and walls. & 4.29 & $(0.74)$ & 0.582 & \\
\hline Opening windows or using air conditioners does not eliminate all smoke particles in a room. & 3.86 & $(0.87)$ & 0.491 & \\
\hline Breathing air in a room today where people smoked yesterday can harm the health of adults. & 4.02 & $(0.84)$ & & 0.721 \\
\hline Particles in rooms where people smoked yesterday can cause cancer. & 3.56 & (0.98) & & 0.675 \\
\hline $\begin{array}{l}\text { Breathing air in a room today where people smoked yesterday can harm the health of infants } \\
\text { and children [17]. }\end{array}$ & 4.21 & $(0.85)$ & & 0.576 \\
\hline $\begin{array}{l}\text { After smoking a cigarette, smoke particles on skin, hair, and clothing can be passed on to } \\
\text { others through touch. }\end{array}$ & 3.67 & (0.99) & & 0.571 \\
\hline $\begin{array}{l}\text { After touching surfaces where cigarette smoke has settled, particles can enter the body } \\
\text { through the skin. }\end{array}$ & 3.47 & $(0.87)$ & & 0.559 \\
\hline
\end{tabular}

Cronbach's alpha: .91 for full scale, .88 for each sub-scale

\section{Beliefs about Thirdhand Smoke scale psychometric properties}

Confirmatory factor analysis showed the good model fit for the two factor model $\left(X^{2}(24)=65.546, p<.0001\right.$, RMSEA $=0.072,90 \%$ CI $($ RMSEA $)=[0.051 ; 0.093]$, CFI $=$ $0.957, \mathrm{TLI}=0.936, \mathrm{SRMR}=0.048$ ). Error covariances between items about THS being harmful to children and to adults were allowed to covary as were items asking about smoke particle transfer through touch and smoke particles entering the body through the skin. Both adjustments improved the a-priori two factor model without error covariances constrained $\left(X^{2}(26)=140.086\right.$, $p<.0001, \quad$ RMSEA $=0.114, \quad 90 \% \mathrm{CI}(\mathrm{RMSEA})=[0.096$; $0.133], \mathrm{CFI}=0.883$, TLI $=0.838, \mathrm{SRMR}=0.061)$. The $\mathrm{a}-$ priori specified model had statistically significantly better fit than a one factor model $\left(\Delta \mathrm{X}^{2}(1)=38.532, p<.0001\right)$. The high correlation between the factors of 0.82 might indicate low convergent validity. However, no factor loadings were weak (i.e. below .40) and most were strong (i.e. greater than .60).

The factor scores as well as the total scale score differed significantly by key participant criteria indicating good construct validity. Those who were in the intervention group and thus were exposed to educational materials on THS scored significantly higher on the total THS scale score as well as the sub-scores than participants in the control group $(p=.0001$ for the full score, $p=.002$ for THS persistence score, $p=.005$ for THS health score). Furthermore, a similar pattern was observed when comparing those who had a full smoking ban in their home compared to those who had a partial or no ban $(p=.001, p=.002, p=.001$, respectively). Participants who owned their homes had higher THS persistence $(p=.04)$ and total scores $(p=.02)$, but had comparable scores on THS health. Smokers had, on average, lower total THS scores $(p=.02)$ and lower THS health scores $(p=.01)$. However, there was no statistically significant difference between smokers and nonsmokers on the THS persistence score. When looking at demographics, the only differences found in THS scores were by educational attainment where those with more education had higher THS persistence scores $(p=.04)$. There were no significant differences in any of the scores by age, gender, race, marital status, income, and employment status.

\section{Discussion}

While prior research [17, 30-32] has used one specific item to measure this construct, the current study is the first to our knowledge to develop a valid and reliable measure of beliefs regarding THS. This is a critical step in research aimed at addressing THS exposure. As smoke-free air policies are more commonly being implemented both in public and in private spaces [17, 31, 32], individual understanding of THS and its impact will be critical in further reducing the harm of tobacco smoke. In particular, intervening on beliefs about THS may prove to be beneficial in reducing THS and SHS exposure. Consequently, the creation of a valid and reliable scale of beliefs regarding THS is critical in assessing these intervention efforts.

This study yielded a valid and reliable 9-item scale assessing this construct, reduced from originally 19 items. The final scale with scoring instructions is available in the Additional file 1. While we had conceptualized five domains, the exploratory factor analysis of the full scale indicates that there are only two distinct domains measured by these 19 items. Interestingly, the two factors that emerged related to: 1) how THS operates within the built environment, i.e. the persistence of smoking particles in indoor spaces, and 2) the impact of THS on health. While the former subscale may 
Table 3 Demographic characteristics of study participants in the validation sample and differences in THS overall scores and sub-scale scores

\begin{tabular}{|c|c|c|c|c|c|c|c|c|c|c|c|}
\hline & \multirow[t]{2}{*}{$\mathrm{N}$} & \multirow[t]{2}{*}{$\%$} & \multicolumn{2}{|c|}{ THS score } & \multirow[t]{2}{*}{$p$-value } & \multicolumn{2}{|c|}{ THS persistence } & \multirow[t]{2}{*}{$p$-value } & \multicolumn{2}{|c|}{ THS health } & \multirow[t]{2}{*}{$p$-value } \\
\hline & & & Mean & $S \mathrm{SD}$ & & Mean & SD & & Mean & $S \mathrm{SD}$ & \\
\hline Full sample & 335 & 100 & 3.92 & 0.63 & & 3.79 & 0.66 & & 3.86 & 0.59 & \\
\hline \multicolumn{12}{|l|}{ Age group (N/\%) } \\
\hline $18-24$ & 25 & $7.5 \%$ & 3.8 & 0.44 & 0.68 & 3.8 & 0.55 & 0.58 & 3.8 & 0.54 & 0.77 \\
\hline $25-39$ & 124 & $37.0 \%$ & 3.8 & 0.55 & & 3.9 & 0.59 & & 3.8 & 0.66 & \\
\hline $40-65$ & 174 & $51.9 \%$ & 3.9 & 0.63 & & 4.0 & 0.67 & & 3.8 & 0.69 & \\
\hline 65 and older & 12 & $3.6 \%$ & 3.7 & 0.59 & & 3.8 & 0.70 & & 3.6 & 0.62 & \\
\hline \multicolumn{12}{|l|}{ Gender (N/\%) } \\
\hline Male & 55 & $16.4 \%$ & 3.8 & 0.68 & 0.46 & 3.8 & 0.72 & 0.2853 & 3.8 & 0.75 & 0.78 \\
\hline Female & 280 & $83.6 \%$ & 3.9 & 0.57 & & 3.9 & 0.62 & & 3.8 & 0.64 & \\
\hline \multicolumn{12}{|l|}{ Marital Status (N/\%) } \\
\hline Married/living with partner & 186 & $55.5 \%$ & 3.8 & 0.59 & 0.49 & 4.0 & 0.65 & 0.48 & 3.8 & 0.67 & 0.58 \\
\hline Single/divorced/separated/widowed & 148 & $44.2 \%$ & 3.9 & 0.59 & & 3.9 & 0.63 & & 3.8 & 0.65 & \\
\hline \multicolumn{12}{|l|}{ Race (N/\%) } \\
\hline White & 48 & $14.3 \%$ & 3.8 & 0.56 & 0.90 & 4.0 & 0.61 & 0.57 & 3.7 & 0.60 & 0.44 \\
\hline African American & 234 & $69.9 \%$ & 3.9 & 0.60 & & 3.9 & 0.64 & & 3.8 & 0.68 & \\
\hline Latina/o & 41 & $12.2 \%$ & 3.9 & 0.58 & & 3.9 & 0.66 & & 3.9 & 0.60 & \\
\hline Other & 12 & $3.6 \%$ & 3.8 & 0.52 & & 3.8 & 0.50 & & 3.7 & 0.69 & \\
\hline \multicolumn{12}{|l|}{ Education (N/\%) } \\
\hline High school graduate/GED or less & 208 & $62.1 \%$ & 3.8 & 0.59 & 0.19 & 3.9 & 0.65 & 0.04 & 3.8 & 0.65 & 0.71 \\
\hline Some college/vocational/technical school & 109 & $32.5 \%$ & 3.9 & 0.56 & & 4.0 & 0.59 & & 3.8 & 0.66 & \\
\hline College graduate or higher & 18 & $5.4 \%$ & 4.1 & 0.68 & & 4.3 & 0.62 & & 3.9 & 0.79 & \\
\hline \multicolumn{12}{|l|}{ Employment (N/\%) } \\
\hline Employed & 91 & $27.2 \%$ & 3.9 & 0.54 & 0.51 & 3.9 & 0.61 & 0.93 & 3.9 & 0.61 & 0.21 \\
\hline Not employed & 240 & $71.6 \%$ & 3.8 & 0.61 & & 3.9 & 0.64 & & 3.8 & 0.68 & \\
\hline \multicolumn{12}{|l|}{ Income (N/\%) } \\
\hline$\$ 10,000$ or less & 154 & $46.0 \%$ & 3.8 & 0.57 & 0.91 & 3.9 & 0.62 & 0.61 & 3.8 & 0.65 & 0.99 \\
\hline$\$ 10,001$ to $\$ 25,000$ & 133 & $39.7 \%$ & 3.9 & 0.62 & & 4.0 & 0.66 & & 3.8 & 0.68 & \\
\hline$\$ 25,001$ to $\$ 50,000$ & 35 & $10.4 \%$ & 3.8 & 0.61 & & 3.9 & 0.62 & & 3.8 & 0.69 & \\
\hline$\$ 50,001$ to $\$ 75,000$ & 6 & $1.8 \%$ & 3.9 & 0.58 & & 4.1 & 0.70 & & 3.7 & 0.55 & \\
\hline More than $\$ 75,000$ & 4 & $1.2 \%$ & 3.9 & 0.17 & & 4.1 & 0.55 & & 3.8 & 0.25 & \\
\hline \multicolumn{12}{|l|}{ Home ownership } \\
\hline Owner & 70 & $20.9 \%$ & 4.0 & 0.62 & 0.04 & 4.1 & 0.66 & 0.02 & 3.9 & 0.68 & 0.13 \\
\hline Resident & 259 & $77.3 \%$ & 3.8 & 0.58 & & 3.9 & 0.62 & & 3.8 & 0.68 & \\
\hline \multicolumn{12}{|l|}{ Home smoking ban } \\
\hline No ban & 70 & $20.9 \%$ & 3.6 & 0.60 & 0.001 & 3.8 & 0.62 & 0.02 & 3.5 & 0.69 & 0.0004 \\
\hline Partial ban & 97 & $29.0 \%$ & 3.8 & 0.58 & & 3.9 & 0.63 & & 3.8 & 0.65 & \\
\hline Full ban & 168 & $50.1 \%$ & 4.0 & 0.57 & & 4.0 & 0.64 & & 3.9 & 0.63 & \\
\hline \multicolumn{12}{|l|}{ Smoking status } \\
\hline Smoker & 202 & $60.3 \%$ & 3.8 & 0.59 & 0.02 & 3.9 & 0.64 & 0.09 & 3.7 & 0.65 & 0.01 \\
\hline Non-smoker & 133 & $39.7 \%$ & 4.0 & 0.58 & & 4.0 & 0.62 & & 3.9 & 0.66 & \\
\hline
\end{tabular}


Table 3 Demographic characteristics of study participants in the validation sample and differences in THS overall scores and sub-scale scores (Continued)

\begin{tabular}{|c|c|c|c|c|c|c|c|c|c|c|c|}
\hline \multicolumn{12}{|l|}{ Group assignment } \\
\hline Intervention group & 158 & $47.2 \%$ & 3.97 & 0.59 & & 4.04 & 0.66 & & 3.89 & 0.65 & \\
\hline Control group & 177 & $52.8 \%$ & 3.76 & 0.57 & 0.001 & 3.82 & 0.59 & 0.002 & 3.69 & 0.66 & 0.005 \\
\hline
\end{tabular}

demonstrate how THS functions within the concrete setting in which smoking occurs, the second measures perceived risk to human health, which is an important theoretical construct related to smoking behavior [33]. In the context of multiunit housing managers or owners, the former may be of particular interest, as they consider the impact of smoking on rental cleanup/deposits or property values [34], and might not be concerned with the negative health effects of smoking on renters.

The scale scores differed, as expected, by smoking status and smoke-free ban status in the home. In addition, we found that those who owned their home scored higher on the THS persistence sub-scale. This might be due to home owners living longer in their home than those who rent and thus observing the persistence of the smell and discoloration of walls or due to homeowners increased interest in preserving property values. However, future studies might explore reasons for those differences. In addition, the intervention participants had higher THS sub- and total scores. Thus, having exposure to educational materials may create awareness of THS, its persistence in the environment and its harms.

There are limitations to the current study. While participants for the pilot study were recruited from across the United States, the validation sample was limited in location to Houston, TX. Thus, findings cannot be extended to those living in different situations. Moreover, this scale should be tested in different populations in varied geographic locations and in those with higher income to explore its external validity. Future studies should test a larger number of possible validity variables. Future research examining how this scale operates alongside measures of perceived risk or harm of smoking, SHS, and receptivity to policies to reduce tobacco smoke exposure could enhance our understanding of the validity of this measure.

\section{Conclusions}

This study has important implications for research and practice. Intervention research that focuses on reducing the harms of tobacco smoke exposure should focus both on the harms/effects of SHS and THS as intervention messages. Therefore, a reliable scale of THS beliefs may be a proxy measure of propensity to lower SHS and THS exposure in homes or other personal spaces such as cars. In addition, examining results across different populations may be helpful in identifying high-risk groups for increased THS exposure and groups more likely to be responsive to interventions that emphasize harm of THS. Practitioners can use the scale to conceptualize intervention experiences to increase understanding of how THS operates within smoke-free homes initiatives that would reduce carcinogens in environments where smoking either still occurs or SHS incursion is a problem.

\section{Additional file}

Additional file 1: Beliefs About ThirdHand Smoke (BATHS)@ scale. (PDF $429 \mathrm{~kb}$ )

\section{Abbreviations \\ BATHS: Beliefs About ThirdHand Smoke; MIMIC: Multiple causes multiple indicators; SFH: Smokefree home; SHS: Secondhand smoke; THS: Thirdhand} smoke

\section{Acknowledgements}

We thank all members of the smoke-free homes team for their contributions to this study.

\section{Funding}

This publication was supported by the National Cancer Institute's State and Community Tobacco Control Research Initiative (grant number U01CA154282). This SFH trial is registered with ClinicalTrials.gov number: NCT02097914. The content is solely the responsibility of the authors and does not necessarily represent the official views of the National Cancer Institute or the National Institutes of Health.

\section{Availability of data and materials}

The dataset analyzed during the current study are available from the corresponding author upon reasonable request.

\section{Authors' contributions}

All authors have contributed to the conception of the paper. $\mathrm{RH}$ has analyzed the data, drafted the methods and results sections, and edited the entire manuscript. CB, CE, LB, and MK have drafted substantial sections of the manuscript, LB has been involved in acquisition of the data. $\mathrm{MH}$ has given substantial input on the study design and drafts of the manuscript. All authors read and approved the final manuscript.

Competing interests

All authors declare that they have no competing interests.

Consent for publication

Not applicable.

Ethics approval and consent to participate

The data for this study come from two sources. The first study was approved as exempt by the Emory University Institutional Review Board. The second study was approved by University of Texas Health Science Center School of Public Health Institutional Review Board. All participants provided informed consent before participating in the studies. 


\section{Author details}

'Department of Behavioral Sciences and Health Education, Rollins School of Public Health, Emory University, 1518 Clifton Rd NE, Atlanta, GA 30322, USA. ${ }^{2}$ Center for Behavioral Epidemiology and Community Health, Graduate School of Public Health, San Diego State University, 9245 Sky Park Court, San Diego, CA 92182, USA

Received: 8 October 2016 Accepted: 6 January 2017

Published online: 17 January 2017

\section{References}

1. Karim ZA, Alshbool FZ, Vemana HP, et al. Third-hand smoke. J Cardiovasc Pharmacol. 2015;66:177-82. doi:10.1097/fjc.0000000000000260.

2. Scotland ASH. Third-hand smoke. 2011.

3. Becquemin $\mathrm{MH}$, Bertholon JF, Bentayeb $\mathrm{M}$, et al. Third-hand smoking: indoor measurements of concentration and sizes of cigarette smoke particles after resuspension. Tob Control. 2010;19:347-8. doi:10.1136/tc.2009. 034694

4. Sleiman M, Gundel LA, Pankow JF, et al. Formation of carcinogens indoors by surface-mediated reactions of nicotine with nitrous acid, leading to potential thirdhand smoke hazards. Proc Natl Acad Sci. 2010;107:6576-81. doi:10.1073/pnas.0912820107.

5. Sleiman M, Logue JM, Luo W, et al. Inhalable constituents of thirdhand tobacco smoke: chemical characterization and health impact considerations. Environ Sci Technol. 2014;48:13093-101. doi:10.1021/es5036333.

6. Thomas JL, Hecht SS, Luo X, et al. Thirdhand tobacco smoke: a tobaccospecific lung carcinogen on surfaces in smokers' homes. Nicotine Tob Res. 2013;16:26-32. doi:10.1093/ntr/ntt110.

7. Matt GE, Quintana PJE, Zakarian JM, et al. When smokers move out and non-smokers move in: residential thirdhand smoke pollution and exposure. Tob Control. 2010;20:e1. doi:10.1136/tc.2010.037382.

8. Dreyfuss JH. Thirdhand smoke identified as potent, enduring carcinogen. CA Cancer J Clin. 2010:60:203-4. doi:10.3322/caac.20079.

9. Burton A. Does the smoke ever really clear? Thirdhand smoke exposure raises new concerns. Environ Health Perspect. 2011;119:a70-4. doi:10.1289/ ehp.119-a70.

10. Matt GE, Quintana PJE, Destaillats H, et al. Thirdhand tobacco smoke: emerging evidence and arguments for a multidisciplinary research agenda. Environ Health Perspect. 2011:119:1218-26. doi:10.1289/ehp.1103500.

11. Matt G, Quintana P, Hovell M, et al. Households contaminated by environmental tobacco smoke: sources of infant exposures. Tob Control. 2004;13:29-37.

12. Yolton $K$, Dietrich $K$, Auinger $P$, et al. Exposure to environmental tobacco smoke and cognitive abilities among U.S. children and adolescents. Environ Health Perspect. 2004;113:98-103. doi:10.1289/ehp.7210.

13. Rehan VK, Sakurai R, Torday JS. Thirdhand smoke: a new dimension to the effects of cigarette smoke on the developing lung. Am J Physiol Lung Cell Mol Physiol. 2011;301:L1-8. doi:10.1152/ajplung.00393.2010.

14. Whitehead TP, Metayer C, Park JS, et al. Levels of nicotine in dust from homes of smokeless tobacco users. Nicotine Tob Res. 2013;15:2045-52. doi: 10.1093/ntr/ntt096

15. Schick S. Thirdhand smoke: here to stay. Tob Control. 2010;20:1-3. doi:10.1136/tc.2010.040279.

16. Escoffery C, Bundy L, Carvalho M, et al. Third-hand smoke as a potentia intervention message for promoting smoke-free homes in low-income communities. Health Educ Res. 2013;28:923-30. doi:10.1093/her/cyt056.

17. Winickoff JP, Friebely J, Tanski SE, et al. Beliefs about the health effects of "thirdhand" smoke and home smoking bans. Pediatrics. 2009;123:e74-9. doi:10.1542/peds.2008-2184.

18. Drehmer JE, Ossip DJ, Rigotti NA, et al. Pediatrician interventions and thirdhand smoke beliefs of parents. Am J Prev Med. 2012;43:533-6. doi:10.1016/j.amepre.2012.07.020

19. Kegler MC, Bundy $L$, Haardörfer $R$, et al. A minimal intervention to promote smoke-free homes among 2-1-1 Callers: a randomized controlled trial. Am J Public Health. 2015:105:530-7.

20. Drehmer JE, Ossip DJ, Nabi-Burza E, et al. Thirdhand smoke beliefs of parents. Pediatrics. 2014;133:e850-6. doi:10.1542/peds.2013-3392.

21. Hovell MF, Hughes SC. The behavioral ecology of secondhand smoke exposure: A pathway to complete tobacco control. Nicotine Tob Res. 2009; 11:1254-64. doi:10.1093/ntr/ntp133.
22. Mullen $P$, Sava $L$, Bundy $Ł$, Haardörfer $R$, Hovell M, Fernández M, Monroy JA, Williams R, Kreuter $M$, Jobe D, Kegler M. Minimal Intervention Delivered by 2-1-1 Information and Referral Specialists Promotes Smoke-Free Homes among 2-1-1 Callers: A Texas Generalization Trial. Tob Contr. 2016;25:110-i18. doi:10.1136/tobaccocontrol-2016-053045.

23. Hang B, Sarker AH, Havel C, et al. Thirdhand smoke causes DNA damage in human cells. Mutagenesis. 2013;28:381-91. doi:10.1093/mutage/get013.

24. Schick SF, Farraro KF, Perrino C, et al. Thirdhand cigarette smoke in an experimental chamber: evidence of surface deposition of nicotine, nitrosamines and polycyclic aromatic hydrocarbons and de novo formation of NNK. Tob Control. 2013:23:152-9. doi:10.1136/ tobaccocontrol-2012-050915.

25. Schick SF, Glantz S. Concentrations of the carcinogen 4(Methylnitrosamino)-1-(3-Pyridyl)-1-butanone in sidestream cigarette smoke increase after release into indoor air: results from unpublished tobacco industry. Cancer Epidemiol Biomark Prev. 2007;16:1547-53. doi:10.1158/ 1055-9965.epi-07-0210.

26. Van Loy MD, Nazaroff WW, Daisey JM. Nicotine as a marker for environmental tobacco smoke: implications of sorption on indoor surface materials. J Air Waste Manag Assoc. 1998;48:959-68.

27. Van Loy MD, Riley WJ, Daisey JM, et al. Dynamic behavior of semivolatile organic compounds in indoor air. 2. nicotine and phenanthrene with carpet and wallboard. Environ Sci Technol. 2001;35:560-7. doi:10.1021/es001372a.

28. Matt GE, Quintana PJE, Fortmann AL, et al. Thirdhand smoke and exposure in California hotels: non-smoking rooms fail to protect non-smoking hotel guests from tobacco smoke exposure. Tob Control. 2013;23:264-72. doi:10. 1136/tobaccocontrol-2012-050824.

29. Di lorio CK. Measurement in health behavior : methods for research and education. San Francisco: Jossey-Bass; 2005

30. Goodman PG, Haw S, Kabir Z, et al. Are there health benefits associated with comprehensive smoke-free laws. Int J Public Health. 2009:54:367-78. doi:10.1007/s00038-009-0089-8.

31. Hahn EJ. Smokefree legislation. Am J Prev Med. 2010;39:S66-76. doi:10.1016/j.amepre.2010.08.013.

32. King BA, Patel R, Babb SD. Prevalence of smokefree home rules-United States, 1992-1993 and 2010-2011. MMWR Morb Mortal Wkly Rep. 2014;63:765-9.

33. Sheeran P, Harris PR, Epton T. Does heightening risk appraisals change people's intentions and behavior? A meta-analysis of experimental studies. Psychol Bull. 2014;140:511-43. doi:10.1037/a0033065.

34. Alamar BC, Glantz SA. Smoke-free ordinances increase restaurant profit and value. Contemp Econ Policy. 2004;22:520-5. doi:10.1093/cep/byh038.

\section{Submit your next manuscript to BioMed Central and we will help you at every step:}

- We accept pre-submission inquiries

- Our selector tool helps you to find the most relevant journal

- We provide round the clock customer support

- Convenient online submission

- Thorough peer review

- Inclusion in PubMed and all major indexing services

- Maximum visibility for your research

Submit your manuscript at www.biomedcentral.com/submit 